\title{
Discurso e materialismo histórico: tensões ideológicas, (re)tomada e (re)significações na mídia impressa brasileira ${ }^{1}$
}

\author{
Rosângela Oliveira Cruz Pimenta ${ }^{2}$ \\ Fabiano Duarte Machado ${ }^{3}$
}

\section{Resumo}

Esta análise desenvolve um estudo sobre a construção/disputa dos sentidos na memória social, a partir do discurso da mídia impressa brasileira, na perspectiva da Análise do Discurso pecheutiana, refletindo sobre o processo de reprodução e contribuindo para um movimento de transformação da práxis social, através do desvelamento da ideologia subjacente à materialidade discursiva analisada. O referencial teórico utilizado foram os estudos de Pêcheux (1990, 1997), Arcary (2004), Orlandi (1983, 1990) e ZoppiFontana (2002). Nosso objetivo é demonstrar como a reportagem da revista Veja sobre os protestos de junho de 2013 constitui efeitos de sentido e direciona posicionamentos cotidianos, do ponto de vista histórico/ideológico. Buscamos observar esse funcionamento à luz de fatos históricos e suas repercussões, materializados na reportagem que, concluímos, cumpre a sua função ideológica: configurar e fixar um imaginário social negativo sobre os manifestantes e os protestos.

Palavras-chave: análise do discurso; ideologia; materialismo histórico-dialético; memória; imprensa

\begin{abstract}
This analysis develops a study about the construction / dispute of the meaning in the social memory, originated by the Brazilian media discourse from the perspective of Pêcheux Discourse Analysis, reflecting on the process of reproduction and contributing for a lot of actions directed to the social praxis transformation through the unveiling of the ideology underlying the discourse materiality analyzed. The theoretical framework was the Pêcheux study $(1990,1997)$, Arcary (2004), Orlandi (1983, 1990) and ZoppiFontana (2002). Our goal is to demonstrate how Veja magazine reports June 2013 protests which constitute effects of meaning and direct daily positions and the historical / ideological point of view. We seek to observe this operation considering the historical facts and their consequences, materialized in the report we concluded that fulfills its ideological function: to configure and set a negative social imaginary of the protesters and protests.
\end{abstract}

Keywords: discourse analysis; ideology; historical and dialectical materialism; memory; press

\footnotetext{
${ }^{1}$ Este trabalho foi originalmente apresentado no VII Seminário de Estudos em Análise do Discurso, em outubro de 2015, na Universidade Federal de Pernambuco.

${ }^{2}$ UFAL/Universidade Federal de Alagoas/Maceió/Alagoas/Brasil, Centro de Educação, rocpiment@yahoo.com.br

${ }_{3}^{3}$ IFAL/Instituto Federal de Alagoas Maceió/Alagoas/Brasil, fabianoduarte.ifal@yahoo.com.br
}

Revista Leitura V.2 no 56 - jul/dez 2015 - Número regular - Autor/a: Rosângela O.C. Pimenta \& 


\section{Introdução}

Os intelectuais orgânicos do capital vão à memória das palavras, através dos aparelhos privados de hegemonia, na atual composição da sociedade civil, das ciências humanas em geral, e em especial da História, com seus arquivos (PÊCHEUX, 1997), trabalhar num ritmo frenético em sua construção/reformulação/destruição/reconstrução do real histórico (passado, presente e futuro), revelando o espírito da luta das classes sociais na construção/reformulação/destruição da hegemonia política, cultural e social.

A corrente discursiva contínua de repetição formal e reformulação parafrástica antipopular, anticomunista, mais recentemente, remonta aos tempos de silêncio fundador $^{4}$ da estruturação/dominação ibérica. Entretanto, a dialética das relações históricas nas suas "esquinas perigosas” (ARCARY, 2004) garante o emergir de acontecimentos discursivos que, nos estertores da luta de classes, produzem frinchas, erosões/deslocamentos nos sentidos que deságuam em "novas estabilizações e reformulações parafrásticas" na memória discursiva, que não foram suficiente para ultrapassar a formação ideológica do capital, última instância "estruturadora" na batalha das classes sociais na estruturação do real histórico (ZOPPI-FONTANA, 2002, p.182183).

Indubitavelmente, esses processos levaram uma grande parte da pequena burguesia, e das camadas médias em geral, ao pânico diante dos supostos "perigos comunistas" aos "pilares da família brasileira" que, com isso, franquearem apoio aos conservadores, como é possível observar na materialidade discursiva afetada pelo interdiscurso e sua dialética das Formações Discursivas nas relações de dominação, subordinação, antagonismo e aliança que determinam os sentidos da sequência discursiva (ZOPPI-FONTANA, 2002, p.179) da revista VEJA que viria a se tornar uma grande porta voz da elite brasileira, alguns anos depois da ditadura militar e até os dias atuais.

A partir dessas considerações, analisamos, a seguir, o corpus - entendido por nós como inesgotável, por entendermos que todo discurso, dialeticamente, constitui relações com discursos anteriores apontando para outros, logo inexistindo discurso fechado em si mesmo, na nossa perspectiva - constituído de sequências discursivas (SD) retiradas da

\footnotetext{
${ }^{4}[\ldots]$ "O silêncio fundador não recorta: ele significa em si. E é ele, afinal, que determina a política do silencio: é porque significa em si que o "não-dizer" faz sentido e faz um sentido determinado. É o silêncio fundador, portanto, que sustenta o princípio de que a linguagem é política”. (ORLANDI, E. P. 1990, p. 51.).
}

Revista Leitura V.2 no 56 - jul/dez 2015 - Número regular - Autor/a: Rosângela O.C. Pimenta \& 
revista Veja, do dia 21/08/2013, mas precisamente da reportagem alusiva aos protestos ocorridos no Brasil em junho de 2013, intitulada: "O bloco do quebra-quebra".

\section{O texto a partir da capa}

Observemos, então, a capa:

Figura 1 - Capa da revista Veja de 21 de ago, 2013

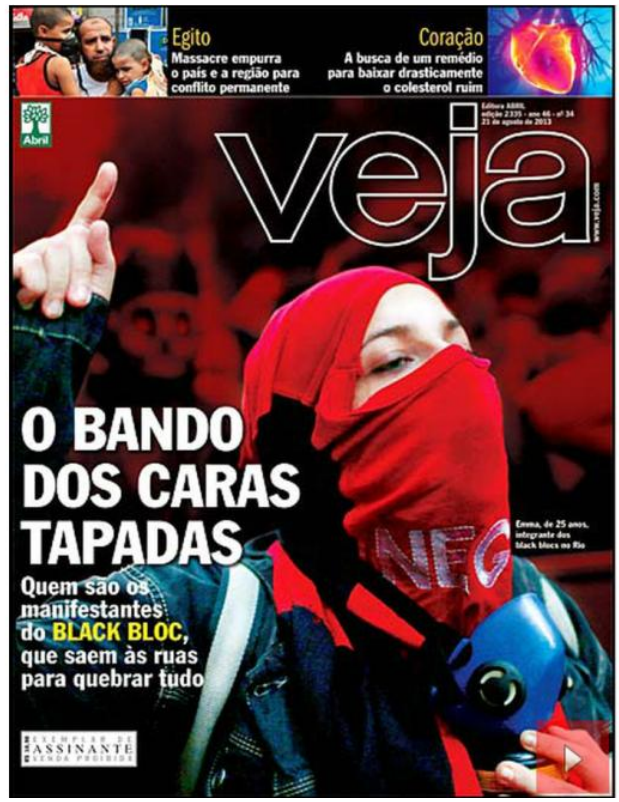

Fonte: Revista Veja ano 46, $n^{\circ} 34$

Vista rapidamente, poderíamos pensar que a capa traz a foto de um marginal, mascarado, que cometeu/comete algum ato perigoso/nocivo e é motivo de ser capa da revista. Num olhar mais detido, temos o título da capa com o termo bando, que se repete inúmeras vezes ao longo do texto, reforçando o imaginário de bandidos, marginais, compondo o enunciado - "O bando dos caras tapadas". Percebe-se, aí, uma retomada da memória do ano de 1992, do "movimento dos caras pintadas" que não foram designados como "bando". Àquela época, os "caras pintadas" tinham como principal propósito o impeachment do então presidente Fernando Collor, apoiado pelos grandes empresários. Hoje, os "caras tapadas" são designados como "bando", num claro processo de deslocamento de sentidos e reformulação parafrástica na tentativa de estabilizar o sentido de que os manifestantes "não teriam um propósito"; seria apenas um "bando de baderneiros", de vândalos. Depois, num olhar ainda mais detido para as condições de produção do funcionamento discursivo dessa materialidade linguísticohistórica, na trama opaca da memória entrelaçada pela ideologia e o esquecimento, 
podemos observar aquilo que é silenciado na escolha simbólica das imagens na disputas/constituição dos sentidos.

A lide da manchete fala que os Black Blocs saem às ruas para "quebrar tudo", silenciando o recado das ruas que anunciavam o mal-estar social e o abismo existente entre as demandas populares por transporte, saúde, educação, habitação e as ações do Estado que patrocinava com recursos públicos os eventos privados da FIFA. De antemão, já é possível apontar o posicionamento assumido pela revista, como determinado na formação ideológica do capital e constituída de seus sentidos numa formação discursiva conservadora adotada ao longo do texto.

\section{Quanto à imagem de abertura}

Figura 1 - Imagem de abertura da reportagem da revista Veja de 21 de agosto de 2013.

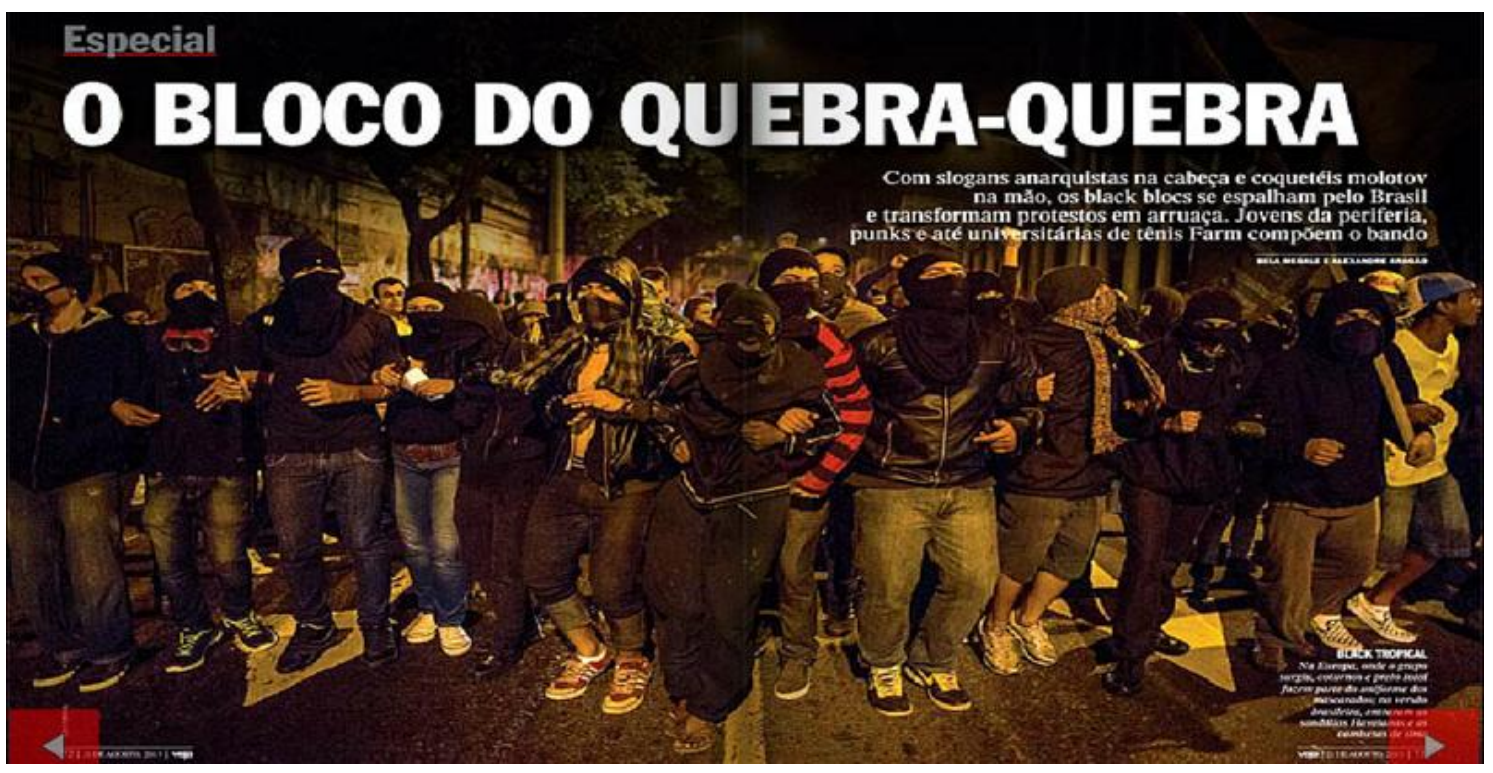

Fonte: Revista Veja ano 46, n 34 , p.72.

Esta imagem de abertura da reportagem apresenta um grupo de jovens, todos mascarados, de braços dados, encabeçando a caminhada do protesto. A frase que acompanha a imagem: "O bloco do quebra-quebra", não faz nenhuma alusão à atitude de defesa, por parte dos Black blocs, dos integrantes da passeata, ante a ameaça da repressão policial, produzindo um efeito leitor de que eles estão "dispostos a quebrar, destruir o patrimônio público", que estão no protesto para isto, silenciando a escolha, realizada pelos Black blocs, por prédios que simbolizam o poder hegemônico do capital 
e do seu Estado burguês. como por exemplos os bancos, palácios de governos, prédios dos legislativos, de concessionárias de veículos, ou seja, símbolos da ordem do capital.

Na mesma imagem, abaixo do título, à direita, há um texto informando ao leitor que os Black Blocs trazem "slogans anarquistas na cabeça e coquetéis molotov nas mãos...”. Onde? Num olhar mais atento entende-se que estas são afirmações recheadas de juízos de valor negativos a respeito deste grupo. Não se vê, nesta foto, nenhum integrante com coquetel molotov. Também há uma informação sobre a constituição deste grupo: jovens da periferia, punks e até universitários. Observem o uso da expressão "até" quando os autores se referem às universitárias. Por que "até"? Pessoas instruídas, estudantes, futuros profissionais deste País não deveriam participar de movimentos reivindicatórios? Os sentidos acionados neste discurso alinham-se à ideia elitista conservadora e preconceituosa de que participar de movimentos como este fica para "os desordeiros", os que moram em periferias, os sem teto, sem emprego, mas jamais para "universitárias de classe média".

Nesta mesma foto, há ainda um texto no final da página, recuado à direita, no qual os autores informam quais os trajes dos Black blocs fora do Brasil e aqui (sandálias havaianas e camisetas de times), estabelecendo uma leve relação de semelhança deste grupo com os integrantes das torcidas organizadas que promovem depredações, violências, tumultos e mortes em dias de jogos.

Ou seja, pode/deve haver, segundo este periódico, uma maneira de estabelecer semelhanças entre as torcidas organizadas e os Black blocs, pois ambos os grupos promovem badernas, arruaças, quebra-quebra, sem nenhum sentido, apenas com a intenção de perturbar a "ordem", de estabelecer o caos. Esta imagem negativa, promovida pela revista está presente ao longo de toda a reportagem e se apresenta também através do jogo de palavras de que os autores lançam mão.

\section{Quanto ao termo protestos}

Além dessas materialidades, destacamos outras contidas no corpo da reportagem, afim de apresentar as diferentes designações utilizadas para referir-se a "protesto".

SD1- "Na semana passada, os Black blocs estiveram por trás de todas as manifestações violentas que explodiram no Rio de Janeiro e em São Paulo...”(p. 74, linhas 26-29) 
SD2 - "e deram até a data, 7 de setembro, quando estão previstas, em dezenas de cidades brasileiras, manifestações de nome preciso e autoexplicativo: "badernaço." (p. 79, linhas 226- 230).

Ao analisarmos os protestos por uma ótica ética e democrática, podemos dizer que eles são a expressão mais democrática e cidadã de um povo. Que, na verdade, está ocorrendo uma crise do sistema capitalista e do Estado que não consegue dar conta dos serviços básicos prestados à população e uma onda cada vez maior e legítima de revolta e indignação por parte da população, em quase todo o mundo, inclusive com 'acenos' de que uma nova ditadura seria bem vinda.

Analisando as sequências acima, observamos que há um caráter depreciativo com o qual que se rotula o movimento dos protestos, usando termos que causam um efeito de repulsa no leitor, como os citados a seguir:

quebra-quebra; anarquistas; coquetéis molotov; arruaça; jovens da periferia; punks; bando; arruaceiros; rosto coberto; destruía; marretadas; destruição; inimigo; vândalos; baderna; violência; assustadora; violentas; que explodiram; mascarados; depredaram; arremessaram; queimado; destruíram; desprezam; abordou aos berros; movimentos sociais decadentes; elementos deletérios; engrossavam; sacudida; protestos; desafiavam; apanhavam; despedaçado; Marxismo em baixa; Anarquismo em alta; aterrissaram; enegrecidas; radicais; não escapam ilesas; grunhidos; grito tribal; provocar; foge; pichar; atear fogo; destruir; evitadas; vandalismo arbitrário; marretadas; golpes; crime; preso; prejuízo; formação de quadrilha; dano; delitos; moldura; males; improvisação; louco; badernaço;ocupa; afugenta; abreviar; isola

Observemos que o uso das palavras selecionadas acima, ao longo do texto, faz com o que o leitor passe a ver, principalmente se não conhece muito bem a proposta dos Black blocs, sua origem, seu histórico, seus costumes, sua ideologia e, principalmente, os contextos em que ocorreram ações desses manifestantes, como algo negativo. Essa forma sutil de persuadir o leitor dá a ele uma falsa impressão de autonomia, quando, na verdade, ele está sendo manipulado pelos autores.

Na SD2, o aposto escolhido revela a visão preconceituosa, conservadora da revista, na qual, de fundo, o que há é a defesa da manutenção do status quo vigente na nossa sociedade capitalista. Quem se rebela contra isto está promovendo baderna. 
O efeito de sentido que estes termos negativos provocam vão direcionando a opinião do leitor de forma direta, fazendo com que não haja solidariedade com quem se expressa, mas que haja desprezo, repulsa por esses atos e, como consequência, a aceitação do conservadorismo que rejeita mudanças.

\section{Quanto ao termo manifestantes}

Em seguida, destacamos as sequências discursivas em que a revista designa, de diferentes formas, os "manifestantes":

SD1- "um bando de arruaceiros com o rosto coberto" (p. 74, linha 09)

SD2- "o bando de inspiração anarquista, defensor da 'destruição consciente da propriedade privada' e autodeclarado inimigo do Capitalismo...” (p. 74, linhas 15-18)

SD3- “..os militantes, por assim dizer...” (p. 74, linhas 19-20)

Ora, no nosso ponto de vista não há distinção entre os manifestantes. Todos que foram às ruas e participaram dos protestos de junho são manifestantes e os Black blocs estão entre eles. Se há, com relação aos Black blocs, uma estratégia ofensiva de destruição dos símbolos do Capitalismo e do Estado opressor, ela deve ser entendida como uma luta ideológica contra alguns símbolos e organizações.

No entanto, a revista faz questão de não reconhecer esse movimento e colocá-los na esteira de jovens burgueses perdidos, arruaceiros, moradores de periferias, bandidos, marginais entre outros. Mas os Black blocs não quebraram casas de família, nem invadiram igrejas, muito menos hospitais e escolas.

A expressão bando, na SD1, nos remete a um imaginário situado: segundo o dicionário Aulete, pode ser "um grupo de ladrões ou criminosos que agem em conjunto; grupo indisciplinado, ou que causa desordem, ou que é marginal às instituições sociais: bando de revolucionários, bando de arruaceiros ou ainda uma quantidade de pessoas (ou, p.ext., de coisas) que têm certa qualidade comum (ger. negativa), mesmo sem formar um grupo coeso: São todos um bando de incompetentes!"

Na SD3, o termo militantes também aciona uma memória depreciativa. Este termo foi usado para designar os jovens de esquerda que lutavam contra a ditadura, na época do governo militar. No entanto, na perspectiva dos militares eram tidos como radicais, tarefeiros de partidos, terroristas. É nessa perspectiva que o termo é acionado para referir-se aos Black blocs. 
Sendo assim, podemos dizer que há uma Formação Discursiva (FD) de matriz dominante no discurso da materialidade em tela, de um sistema capitalista-conservador, que é pró-situação, de direita, do governo, e que as sequências discursivas pertencem a esta matriz, assim como os termos negativos que foram selecionados acima, produzindo uma ideologia que é contra a ética, a democracia, os direitos humanos, contra o povo, a corrupção e a força de organização.

\section{Conclusões}

Podemos observar, em termos de conclusões iniciais, que a história é totalmente aberta, no tocante à luta de classes, seus movimentos e gestos de leituras, pois mobilizam arquivos sociais na construção da subjetividade produzida nas agudas contradições aprisionadas nos corações e mentes da formação social brasileira, que entende como perigo a mais legítima forma de democracia: o direito de se posicionar criticamente, seja para concordar ou discordar. A reportagem analisada, cumpre, então, o seu papel ideológico, pois ao se sentir ameaçada, a sociedade rejeita formas de expressão coletivas, configurando e fixando um imaginário social negativo sobre os manifestantes e os protestos.

\section{Referências}

ARCARY, V. As esquinas perigosas da História: situações revolucionárias em perspectiva marxista. 1.ed. São Paulo: Xamã, 2004.

DICIONÁRIO AULETE. Disponível em: www.aulete.uol.com.br. Acesso em 16 de jan de 2014.

MEGALE, B.; ARAGÃO, A. O bloco do quebra-quebra. Revista Veja, edição 2325, ano 46, N. ${ }^{\circ}$ 34, de 21/08/2013, São Paulo: Editora Abril, 2013.

ORLANDI, E.P. A linguagem e seu Funcionamento: as formas do discurso. São Paulo: Brasiliense, 1983.

ORLANDI, E.P. A Terra à vista! : discurso do confronto: velho e novo mundo. São Paulo: Cortez, 1990.

PÊCHEUX, M. O Discurso: estrutura ou acontecimento. Campinas, SP: Pontes, 1990, p. 19-28.

Semântica e Discurso. $3^{\text {a }}$ ed. Campinas, SP: Editora da Unicamp, 1997.

Revista Leitura V.2 no 56 - jul/dez 2015 - Número regular - Autor/a: Rosângela O.C. Pimenta \& 
ZOPPI- FONTANA, Mônica G. Acontecimento, Arquivo, Memória: Às margens da lei. In Leitura - Discurso: história, sujeito e ideologia: n. 30, jul. 2002-dez, p. 182-183. 